\title{
Prevalence of atopy and exercise-induced bronchial lability in relatives of patients with cystic fibrosis
}

\author{
RALPH COUNAHAN* and MARGARET B. MEARNS \\ From Queen Elizabeth Hospital for Children, London
}

\begin{abstract}
Counahan, R., and Mearns, M. B. (1975). Archives of Disease in Childhood, 50, 477. Prevalence of atopy and exercise-induced bronchial lability in relatives of patients with cystic fibrosis. Skin tests and exercise tests were performed on children with cystic fibrosis (CF) and first-degree relatives of CF children. Positive skin tests were found in $56 \%$ of patients and $19 \%$ of relatives, but the prevalence of atopy in CF patients bore no relationship to its prevalence in their relatives. Increased bronchial lability, mainly due to bronchoconstriction, was present in $54 \%$ of patients and $27 \%$ of relatives. The results showed that increased prevalence of bronchial lability, but not atopy, is found in first-degree relatives of $\mathrm{CF}$ children, and that the abnormal lability and atopy found in CF children does not indicate a familial allergic background.
\end{abstract}

Abnormal exercise-induced bronchial lability and skin atopy have been shown in patients with cystic fibrosis (CF). Day and Mearns (1973) reported that only $27 \%$ of 52 children with CF had normal bronchial lability in response to exercise, and McCarthy, Pepys, and Batten (1969) found that $43 \%$ of $57 \mathrm{CF}$ patients had positive skin reactions to common allergens. A higher than normal prevalence of increased bronchial lability and skin atopy has been shown in the relatives of children with asthma and of infants with wheezy bronchitis (König and Godfrey, 1973a, b). The present study was done to determine the prevalence of abnormal bronchial lability and skin atopy in children with CF and their first-degree relatives.

\section{Subjects and methods}

Thirty-five children with $\mathrm{CF}$ and 59 first-degree relatives (37 parents and 22 sibs) were studied. The children attended this hospital between July 1973 and January 1974 and at the times of testing they were free of acute infection. The relatives were all volunteers and the purpose of the study was explained to them. Some of the relatives of patients were too young to be exercised, and some of the younger patients and relatives refused skin testing. The mean age of the patients tested was $10 \cdot 2$ years $(4-18)$, sibs $11 \cdot 5$ years $(6-18)$, and parents $37 \cdot 3$ years $(27-54)$.

Received 27 November 1974.

^Present address: The Hospital for Sick Children, Great Ormond Street, London WCIN 3JH.
Clinical histories were taken from the relatives and they were classiffied as being atopic (past or present asthma, hayfever, allergic rhinitis, infantile or flexural eczema) or healthy. Smoking habits were recorded. Skin testing was carried out on patients and relatives by prick test with a control and the following allergens: Dermatophagoides pteronyssinus, milk, cat fur, dog hair, early summer flower pollens, Aspergillus fumigatus and mixed aspergilli (Bencard $\mathrm{M}_{2}$ combining Asperigillus amsteldami, niger, and terreus).

Exercise tests were performed by the subjects running on a treadmill for 6 minutes at a slope of 10 degrees and at a speed of 3-4 mph, the speed being adjusted to give a pulse rate of approximately $170 / \mathrm{min}$ (Connolly and Godfrey, 1970). Before testing the patients were given routine percussion physiotherapy. The peak expiratory flow rate (PEFR) was measured by a Wright Peak Flow meter before exercise, at 2-minute intervals during exercise, and for 15 minutes afterwards. In each case the best of 3 efforts was recorded. Bronchodilator aerosol was not used. Indices were calculated as below. Normal values for PEFR were taken from Nairn et al. (1961). The upper limits of normal for the indices were taken from the data of Silverman and Anderson (1972). Bronchial lability was considered abnormal if any of the indices were abnormal. The Jones lability index (Jones and Jones, 1966) was modified by the use of PEFR instead of forced expiratory volume at $1 \mathrm{~s}$, and by omitting bronchodilators.

The results were examined first in relation to all the subjects, and secondly for intrafamily findings in a subgroup of 38 relatives of 17 patients. The means of the indices for different groups were compared by Student's ' $t$ ' test. 
Percentage rise $=$

highest PEFR during exercise - resting PEFR

resting PEFR

Percentage fall $=$

resting PEFR - lowest PEFR after exercise

resting PEFR
Exercise lability index $(\mathrm{ELI})=100(\%)$
percentage fall
Modified Jones lability index $(\mathrm{JLI})=$
highest PEFR - lowest PEFR

expected normal PEFR

\section{Results}

History. An adequate history was obtained from 58 relatives, and 12 gave a history of atopy. In some the evidence for atopy was slight, e.g. hayfever for 2 consecutive years in the distant past without further recurrence.

\section{Skin tests.}

All subjects. 10 of 53 relatives and 13 of 23 patients (19\% and $56 \%$, respectively) who were skin tested had an abnormal response to 1 or more allergens (Table I). D. pteronyssinus and cat fur

TABLE I

Allergens producing a positive skin test

\begin{tabular}{l|c|c}
\hline Allergen & $\begin{array}{c}\text { No. (and \%) } \\
\text { of relatives (53) }\end{array}$ & $\begin{array}{c}\text { No. (and \%) } \\
\text { of patients (23) }\end{array}$ \\
\hline D.pteronyssinus & $4(8)$ & $6(26)$ \\
A.fumigatus & $1(2)$ & $8(35)$ \\
Milk & $2(4)$ & $3(13)$ \\
Cat fur & $4(8)$ & $5(26)$ \\
Dog hair & $5(8)$ & $3(13)$ \\
Pollens & $1(2)$ & $3(13)$ \\
\hline
\end{tabular}

were the commonest allergens producing a positive response in relatives, and $A$. fumigatus/mixed aspergilli the commonest in patients. There was no significant difference in the prevalence of atopy among the relatives of atopic and nonatopic patients (Table II).

Atopic history and skin tests. 53 relatives from whom a history concerning presence or absence of atopy had been obtained were skin tested. Positive response was found to 1 or more allergens in 4 of 43 healthy and 6 of 10 atopic subjects $(9 \%$ and $60 \%$, respectively).
TABLE II

Skin atopy and bronchial lability in 38 relatives of 17 patients

\begin{tabular}{l|c}
\hline 9 Atopic patients & \\
Atopic relatives & $3(8 \%)$ \\
Nonatopic relatives & $15(39 \cdot 5 \%)$ \\
8 Nonatopic patients & $3(8 \%)$ \\
Atopic relatives & $17(44 \cdot 5 \%)$ \\
Nonatopic relatives & $7(18 \cdot 5 \%)$ \\
9 Labile patients & $15(39 \cdot 5 \%)$ \\
Labile relatives & $3(8 \%)$ \\
Nonlabile relatives & Nonlabile patients \\
Labile relatives & $13(34 \%)$ \\
Nonlabile relatives & \\
\hline
\end{tabular}

\section{Exercise tests.}

Relatives. 27 male and 29 female relatives were studied. Increased bronchial lability was found in $15(27 \%), 6$ males and 9 females. The increased lability was found in 6 of 22 sibs (27\%) and 9 of 34 parents $(26 \%$ ), showing that abnormal lability was equally distributed between adults and children. Relatives who smoked were equally distributed between labile and nonlabile groups.

Increased lability was mainly due to bronchoconstriction, 10 of the 15 relatives having an abnormal percentage fall alone. 2 had an abnormal percentage rise alone and 1 had both abnormal percentage rise and percentage fall. One subject had an abnormal modified Jones Lability Index without abnormal percentage rise or fall, due to resting PEFR being much higher than predicted.

Patients. 20 male and 15 female patients were exercised. Increased lability was found in 19 $(54 \%), 12$ being male. 8 of the 19 patients had an abnormal percentage rise; in 5 this was not associated with an abnormal percentage fall. 14 patients had an abnormal percentage fall; in 11 this was not associated with an abnormal percentage rise.

38 relatives of 17 patients. There was no significant difference in the prevalence of increased bronchial lability in this group of relatives compared to the group as a whole, $26 \%$ being abnormally labile. There was trend towards increased lability in the relatives of labile patients, but the numbers were not large enough to be conclusive (Table II).

Atopic history and exercise tests. 55 relatives, from whom a history had been obtained, had exercise tests. Abnormal bronchial lability was 
TABLE III

Indices of exercise lability in CF patients and their relatives

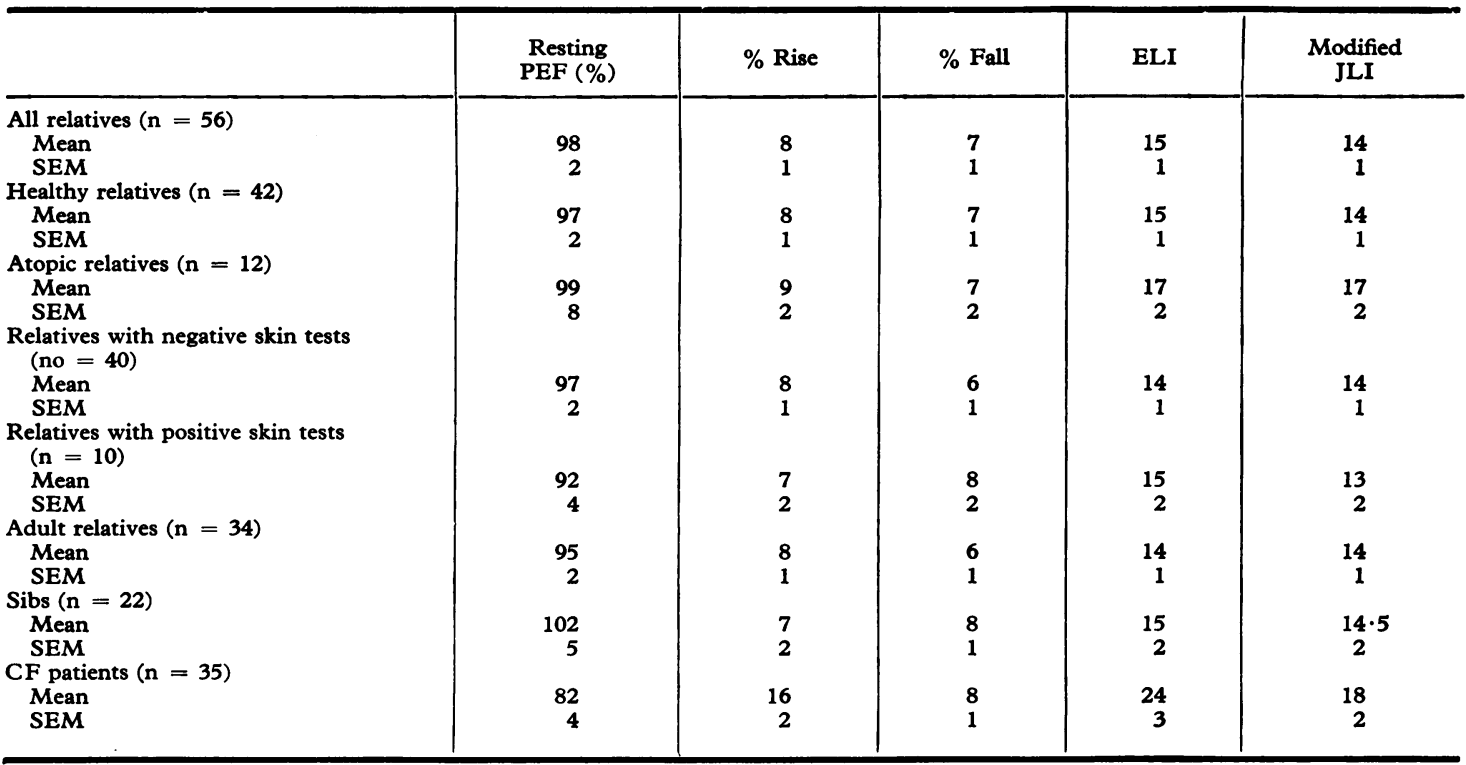

found in 9 of 43 healthy and 5 of 12 atopic subjects $(21 \%$ and $42 \%$, respectively). A slightly higher percentage of the healthy childhood relatives were abnormally labile compared to the healthy adults, but the difference was not significant as numbers were small.

Patients' histories and relatives' exercise tests. 31 relatives of 7 patients with a definite history of wheezing were exercised and $7(23 \%)$ were found to be abnormally labile.

Mean values for the indices of exercise lability. Examination of the mean indices (Table III) showed a difference $(P=0.001)$ between patients and relatives, except in the percentage fall index, in which there was no significant difference between the groups; the difference in the modified Jones Lability Index was at 5\% significance level. Despite the fact that a greater proportion of both relatives and patients showed bronchoconstriction, the degree of bronchodilatation was equal in the relatives overall and considerably greater in the patients. The differences between the patients and sibs were less marked though still significant. For PEF \% and \% Rise, $P=<0.01$; for Exercise Lability Index, $\mathbf{P}=<0 \cdot 05$. Significant differences between sibs and adults could not be shown, however. The higher prevalence of in- creased bronchial lability in atopic relatives compared to nonatopic relatives was not reflected in the mean figures.

\section{Comparison of skin and exercise tests.}

Relatives. 50 relatives had both skin and exercise tests, showing that the prevalence of abnormal bronchial lability among atopic and nonatopic subjects as assessed by skin testing was constant, though the numbers in the atopic group were small (Table IV).

\section{TABLE IV}

Comparison of skin and exercise tests in 50 relatives of CF patients

\begin{tabular}{l|c}
\hline With positive skin tests (10) & \\
Labile & $2(20 \%)$ \\
Nonlabile & $\mathbf{8}(80 \%)$ \\
With negative skin tests (40) & $9(22 \cdot 5 \%)$ \\
Labile & $31(77 \cdot 5 \%)$ \\
Nonlabile & \\
\hline
\end{tabular}

Patients. 21 patients had both tests and again, though numbers were small, the prevalence of abnormal bronchial lability in atopic and nonatopic subjects was similar. 6 of 11 atopic and 7 of 10 nonatopic subjects were abnormally labile. 


\section{Discussion}

In the present study $54 \%$ of patients with CF had increased lability. This was less than in the study of Day and Mearns (1973), who found increased lability in $73 \%$ of the CF patients tested. The type of exercise may in part account for this difference, in that they used free-range running. Anderson, Connolly, and Godfrey (1971) have shown that free-range running is a slightly more potent stimulus to induce postexercise bronchoconstriction than treadmill running. Treadmill walking did not induce increased lability in a group of CF children reported by Heimlich, Strick, and Busser (1966).

Increased lability in the present study was due more to bronchoconstriction than to bronchodilatation, 11 of 19 abnormally labile patients having bronchoconstriction alone, 3 having both bronchoconstriction and bronchodilatation, and 5 having bronchodilatation alone. This contrasted with the findings of Day and Mearns (1973) who found increased lability in CF patients to be due more to bronchodilatation. They had a greater proportion of more severely affected patients than in the present study, and these were not only more labile but also showed increased dilatation more frequently than the less severely affected patients.

Increased prevalence of bronchial lability in response to exercise was shown in the present study in the families of children with CF. The prelence in both the nonatopic and atopic relatives was different from that in a normal population reported by König and Godfrey (1973a, b), who found that $2(8 \%)$ of 24 control subjects in their study had abnormal bronchial lability. However, atopic relatives of CF patients showed a similar prevalence to the atopic relatives of their patients with wheezy bronchitis and asthma (Table V). While the abnormal lability in the present study seemed to be related to the atopic status as assessed by the history, this was not borne out by comparing it to the results of skin tests. An inherited mechanism, probably different to that in asthma and wheezy bronchitis, may be responsible for these findings in some relatives. Other variable and unrelated findings have been shown in the heterozygotes for $\mathrm{CF}$ and are not sufficiently constant to be used as a means of identification (Spock et al., 1967; Danes and Bearn, 1968).

Increased prevalence of atopy was found in the relatives of children with wheezy bronchitis and asthma (König and Godfrey, 1973b), but in the present study of the relatives of CF patients the prevalence of atopy was found to be less than in the control population. Prevalence of positive skin tests was less both in the nonatopic and atopic relatives than in the control population.

A different pattern of bronchial lability was found in the relatives of the CF patients, who showed mainly bronchoconstrition in response to exercise, whereas the relatives of children with asthma and of infants with wheezy bronchitis were reported to show mainly bronchodilatation. The mean figures for percentage rise and percentage fall do not reflect this, however.

The family study of 38 relatives of 17 patients showed that apart from the previously mentioned trend towards increased lability in the relatives of labile patients, neither atopy in patients or relatives as assessed by skin testing, nor a patient's history of acute airways obstruction influenced the findings. Acute airways obstruction in CF patients may differ in some cases from that in asthma in its mechanism, which may be similar to that in chronic obstructive bronchitis. Gimeno et al., (1974) found that exercise-induced airways obstruction can be a manifestation of disease associated with chronic airways obstruction and independent of the response

\section{TABLE V}

Skin and exercise tests in relatives of $C F$ patients, compared ${ }^{\star}$ with relatives of patients with wheezy bronchitis and asthma and relatives of controls.

\begin{tabular}{l|c|c|c|c}
\hline & Controls & Wheezy bronchitis & Asthma & Cystic fibrosis \\
\hline No. of healthy relatives & 20 & 31 & 25 & 40 \\
\% Positive skin tests & 20 & 53 & 40 & 10 \\
$\%$ Positive exercise tests & 5 & 29 & 32 & $17 \cdot 5$ \\
\hline No. of atopic relatives & 4 & 7 & 28 & 10 \\
\% Positive skin tests & 75 & 71 & 79 & 40 \\
$\%$ Positive exercise tests & 25 & 29 & 39 & \\
\hline
\end{tabular}

^Data from König and Godfrey (1973a, b). 
of the airways to histamine. Clearly, asthma and cystic fibrosis may coexist, and in this study the best indication was the history rather than skin tests.

Increased atopy in patients as evidenced by skin tests confirms the findings of Mearns, Longbottom, and Batten (1967), who reported that $38 \%$ of $86 \mathrm{CF}$ patients had positive reactions to $A$. fumigatus. McCarthy et al. (1969) found that $49 \%$ of 37 older CF patients had positive skin reactions to $A$. fumigatus. $48 \%$ of the patients in the present study had positive skin reactions to common allergens compared to $43 \%$ in the group studied by McCarthy et al. The results of skin testing the relatives of $\mathrm{CF}$ patients are not significantly different from those expected in a normal population. Allergy does not appear to be a dominant factor in the aetiology of the increased bronchial lability in the relatives of CF patients; it is possible that inherited factors could be responsible, but this could not be determined.

We are grateful to Dr. A. D. M. Jackson for permission to include patients under his care in this study.

\section{REFERENCES}

Anderson, S. D., Connolly, N. M., and Godfrey, S. (1971). Comparison of bronchoconstriction induced by cyling and running. Thorax, 26, 396.

Connolly, N. M., and Godfrey, S. (1970). Assessment of the child with asthma. Fournal of Asthma Research, 8, 31.
Danes, B. S., and Bearn, A. G. (1968). A genetic cell marker in cystic fibrosis of the pancreas. Lancet, $1,1061$.

Day, G., and Mearns, M. B. (1973). Bronchial lability in cystic fibrosis. Archives of Disease in Childhood, 48, 355.

Gimeno, F., Berg, W.Chr., Steenhuis, E. J., de Vries, K., Peset, R., and Sluiter, H. J. (1974). Exercise-induced airway obstruction in relation to chronic obstructive lung disease. Thorax, 29, 16.

Heimlich, E. M., Strick, L., and Busser, R. J. (1966). An exercise response test in childhood asthma. (Abstr.). fournal of Allergy, 37, 103.

Jones, R. H. T., and Jones, R. S. (1966). Ventilatory capacity in young adults with a history of asthma in childhood. British Medical fournal, 2, 976.

König, P., and Godfrey, S. (1973a). Prevalence of exercise-induced bronchial lability in families of children with asthma. Archives of Disease in Childhood, 48, 513.

König, P., and Godfrey, S. (1973b). Exercise-induced bronchial lability and atopic status of families of infants with wheezy bronchitis. Archives of Disease in Childhood, 48, 942.

McCarthy, D. S., Pepys, J., and Batten, J. (1969). Hypersensitivity to fungi in cystiz fibrosis. Proceedings of the 5th International Cystic Fibrosis Conference, Cambridge, p.194. Ed. by D. Lawson. Cystic Fibrosis Research Trust, London.

Mearns, M., Longbottom, J., and Batten, J. (1967). Precipitating antibodies to aspergillus fumigatus in cystic fibrosis. Lancet, $1,538$.

Nairn, J. R., Bennet, A. J., Andrew, J. D., and MacArthur, P. (1961). A study of respiratory function in normal school children. Archives of Disease in Childhood, 36, 253.

Silverman, M., and Anderson, S. D. (1972). Standardization of exercise tests in asthmatic children. Archives of Disease in Childhood, 47, 882.

Spock, A., Heick, H. M. C., Cress, H., and Logan, W. S. (1967). Abnormal serum factor in patients with cystic fibrosis of the pancreas. Pedictric Research, 1, 173.

Correspondence to Dr. M. B. Mearns, Queen Elizabeth Hospital for Children, Hackney Road, London E2 8PS. 